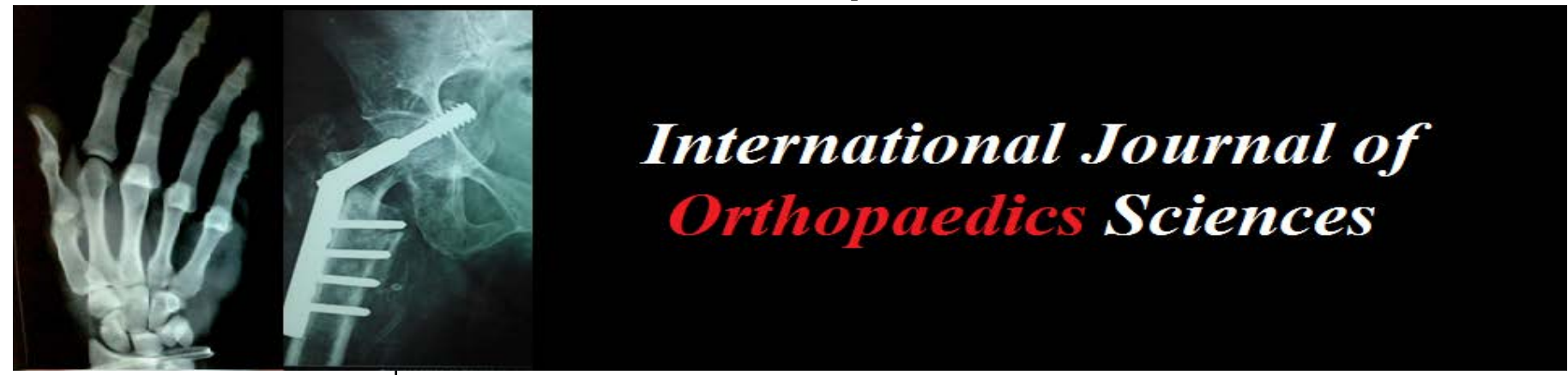

E-ISSN: 2395-1958

P-ISSN: 2706-6630

IJOS 2020; 6(1): 58-62

(C) 2020 IJOS

www.orthopaper.com

Received: 12-11-2019

Accepted: 16-12-2019

Dr. Jana Sai Shankar Junior Resident, Department of Orthopaedics Mamata Medical College, Khammam, Telangana, India

Dr. Sujith Kumar Vakati Assistant Professor, Department of Orthopaedics, Mamata Academy of Medical Sciences, Bachupally, Hyderabad, Telangana, India
Corresponding Author: Dr. Sujith Kumar Vakati Assistant Professor, Department of Orthopaedics, Mamata Academy of Medical Sciences, Bachupally, Hyderabad, Telangana, India

\section{Study of functional outcome of two, three and four-part proximal humerus fracture fixation with locking compression plate using Neer`s score}

\author{
Dr. Jana Sai Shankar and Dr. Sujith Kumar Vakati
}

DOI: https://doi.org/10.22271/ortho.2020.v6.i1b.1837

Abstract

Proximal Humerus fractures are one of the commonest fractures occurring in the orthopedics. They comprises of approximately $4-5 \%$ of the fractures at the hospital and are secondary only to hip fractures and distal end radius fractures in the elderly group. The incidence is approximately 3 per 1000 persons in a year and is rapidly increasing with age. They are common in elderly patients after cancellous bone of the humeral neck has weakened due to old age, but these fractures can be seen in any age group. The most serious fractures and fracture-dislocations are often seen in active middle aged patients. These fractures can be extremely disabling and their management often demands expertise surgical skills and judgment. 2 Because of increasing incidence of high energy trauma complicated patterns of fracture in proximal humerus are becoming increasingly common. The preferred treatment varies depending on the age of patient, bone quality, expertise surgical team and the patient's expectations. There is a controversy regarding the best method of treating displaced proximal humerus fractures.

Treatment options for displaced fractures include open reduction and internal fixation. Neer recommended Open reduction \& internal fixation for 2- and 3-part fractures. Most of the poor results following open reduction and internal fixation of these fractures are due to imperfect surgical techniques. In a three or four-part fracture dislocation when the Humerus head is entirely devoid of any blood supply it can be replaced by prosthesis. This study is about the use of Locking Compression Plate to fix fractures of the proximal humerus in adult patients in whom the duration of hospital stay reflects the earning capacity of the person and in elderly in whom immobilization of upper-limb is associated with stiffness, reflex sympathetic dystrophy, and shoulder-hand syndrome.

Keywords: Proximal humerus, locking compression plate, NEER’s score

\section{Introduction}

Objectives

- To assess patients Outcome with proximal humerus fractures treated with Locking compression plate post-operatively using Neer`s score.

- To Compare patients outcome with proximal humerus fractures treated with locking compression plate post operatively using Neer’ s score

\section{Methods}

Percutaneous Pins and External Fixation: Percutaneous pinning is done after a closed reduction if the reduction is unstable. It is particularly useful in the treatment of un-impacted 2part fractures of the surgical neck, but can be used with limitation in more complex fracture patterns as well. Multiplanar fixation and increasing the number of cortex purchased increases the fixation stability.

Open reduction and internal fixation: Various techniques and devices are proposed for the treating of proximal humeral fractures. The choice depends on various factors including the fracture type, bone quality, condition of soft tissue, age and reliability of the patient.

Open reduction and internal-fixation is commonly recommended for three-part displaced fractures. 47 It is also used in some two-part displaced fractures, and can be used in four part fractures in young patients. 
The goal of open reduction and internal fixation is to stabilize the fracture and promote healing while allowing early shoulder movements to reduce the risk of stiffness.

Prosthetic Replacement: Primary hemiarthroplasty is sometimes used for the treating of proximal humeral fractures.48 It is usually recommended for head splitting fracture type, four part fractures and anatomical neck fracture dislocation especially in the elderly. $49 \quad$ Four- part fractures in patients less than 40 years, and where the head retains its continuity with the glenoid, may be treated by open reduction and internal fixation despite the risk of developing avascular necrosis.

All patients with proximal humerus fractures were admitted to the hospital, all the necessary clinical details were recorded in the trauma sheet comprising of

1. Age of the patient.

2. History of trauma whether injury was due to fall or road traffic accident.

3. Time and place of injury.

4. Time interval between injury and treatment in our casualty department.

5. Occupation of the patient.

6. Associated injuries.

7. Medical history of the patient,

\section{Inclusion criteria}

- All patients admitted with proximal humerus fracture [Neer ${ }^{\text {ee }}$ s classification: Part 2, part 3 and part 4] who are medically fit for surgery.

- Patients above 18 years of age. Exclusion criteria:

- Patients with axillary nerve damage.

- Patients with fracture dislocations of the head of the humerus.

- Patients with anatomical neck fractures with dislocation in elderly.

- Isolated fractures of greater or lesser tuberosity.

- Cases with previous infection/affection of the shoulder.

\section{Operative Technique}

Surgical exposure in all cases was delto-pectoral approach to shoulder and humerus.

1. Patients were given a preoperative dose of intravenous first generation cephalosporin antibiotics.

2. Patients were put in supine position.

3. Small sand bags were kept under the affected side of the scapula to elevate the shoulder and allow the arm to fall backward, thereby opening up the front of the shoulder.

4. 10- $15 \mathrm{~cm}$ incision was taken over the delto-pectoral groove extending from deltoid insertion distally to coracoids process proximally.

5. Inter-nervous avascular plane between deltoid and pectoralis major developed after ligating and retracting cephalic vein.

6. Pectoralis major muscle retracted medially and deltoid retracted laterally. The biceps tendon acts as a guide to the interval between the greater and lesser tuberosities. It also acts as a guide to the rotator interval between the anterior part of the supraspinatus and the superior edge of the subscapularis.

7. The insertion of the pectoralis major were identified distally and periosteum incised laterally and bone was exposed subperiosteally to avoid damage to the radial nerve. The short head of biceps and coracobrachialis were displaced medially and anterior aspect of shoulder was exposed.

8. The arm was kept abducted throughout the surgery to prevent damage to the axillary artery and the brachial plexus. Greater tuberosities were exposed under cover of deltoid muscle

9. Analysis of the fracture geometry was done. If it was associated with dislocation then capsule is incised and head fragment is reduced first. Before the replacement of the tuberosities all the cancellous bone debris and hematoma were removed.

10. After achieving the temporary anatomical reduction with $\mathrm{k}$-wires, it was fixed with proximal humerus Locking Compression Plate under image control guidance

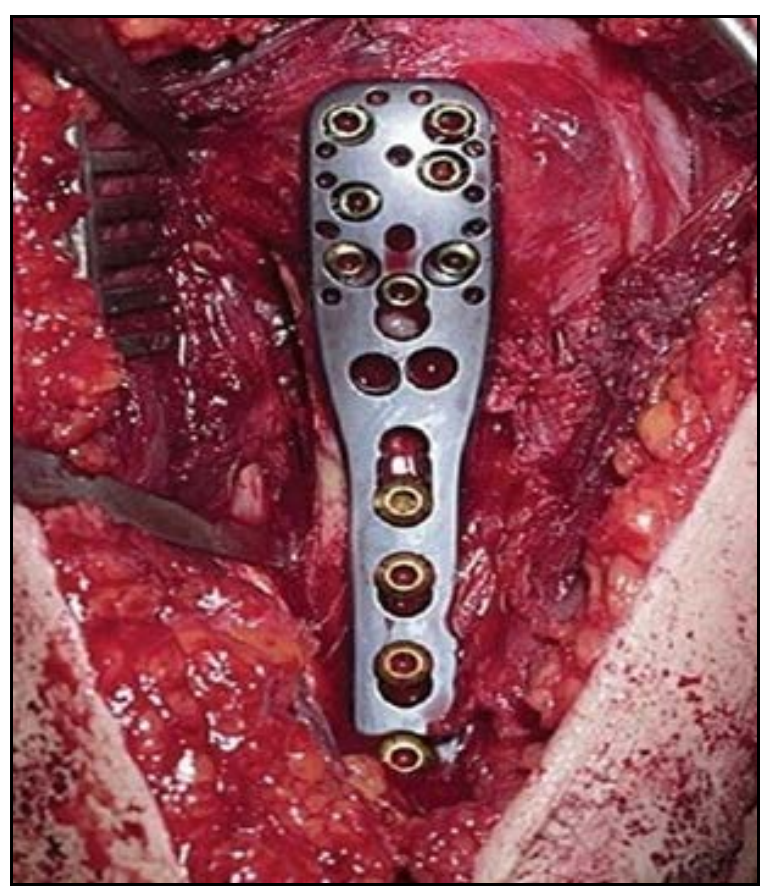

Fig 1: LCP in Position

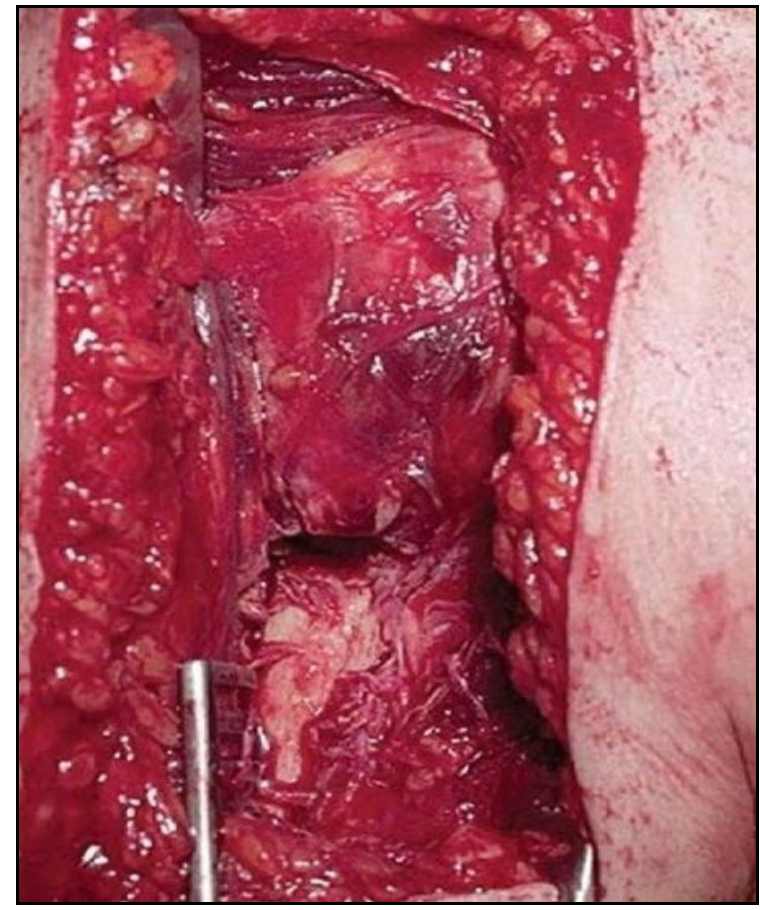

Fig 2: Exposure of Fracture Site

Evaluation of the Post-Operative Results

Neer. S Cri Teria 
Table 1: Pain

\begin{tabular}{|c|c|}
\hline Degree of pain & Points \\
\hline No pain & 35 \\
\hline Slight or occasional pain & 30 \\
\hline Mild not affecting daily life & 25 \\
\hline Moderate,tolerable.affects daily activity & 15 \\
\hline Marked,serious limitation of activity & 05 \\
\hline Totaldisablement & 00 \\
\hline
\end{tabular}

Table 2: Functional Ability

\begin{tabular}{|c|c|c|c|c|c|}
\hline \multicolumn{2}{|c|}{ Strength } & \multicolumn{2}{c|}{ Reaching } & \multicolumn{2}{c|}{ Stability } \\
\hline Normal & 10 & Above head & 02 & Lifting & 02 \\
\hline Good & 08 & Mouth & 02 & Throwing & 02 \\
\hline Fair & 06 & Belt buckle & 02 & carrying & 02 \\
\hline Poor & 04 & Opposite & 02 & Pushing & 02 \\
\hline Trace & 02 & Brassiere hook & 02 & Hold over head & 02 \\
\hline Zero & 00 & & & & \\
\hline
\end{tabular}

Table 3: Range

\begin{tabular}{|c|c|c|c|c|c|c|c|c|c|}
\hline \multicolumn{2}{|c|}{ Flexion } & \multicolumn{2}{|c|}{ Extension } & \multicolumn{2}{|c|}{ Abduction } & \multicolumn{2}{|c|}{ External rotation } & \multicolumn{2}{|c|}{ Internal rotation } \\
\hline 180 & 6 & 45 & 3 & 180 & 6 & 60 & 5 & 90 & 5 \\
\hline 130 & 4 & 30 & 2 & 170 & 5 & 30 & 3 & 70 & 3 \\
\hline 100 & 2 & 15 & 1 & 140 & 4 & 10 & 1 & 50 & 1 \\
\hline 80 & 1 & $<15$ & 0 & 100 & 2 & $<10$ & 0 & 30 & 2 \\
\hline$<80$ & 0 & & 80 & 1 & & & $<30$ & 0 \\
\hline & & & $<80$ & 0 & & & & \\
\hline
\end{tabular}

Table 4: Degree of Deformity (Anatomy)

\begin{tabular}{|c|c|}
\hline None & $\mathbf{1 0}$ \\
\hline Miki & 08 \\
\hline Moderate & 04 \\
\hline severe & 02 \\
\hline
\end{tabular}

Maximum points using Neer's criteria 1s 100 units on overall scores, the patient are grouped into

\section{Results}

Table 5: Outcome

\begin{tabular}{|l|l|}
\hline Excellent & $>89$ units \\
\hline Satisfactory & $80-89$ units \\
\hline Unsatisfactory & $70-79$ units \\
\hline Failure & $<70$ units \\
\hline
\end{tabular}

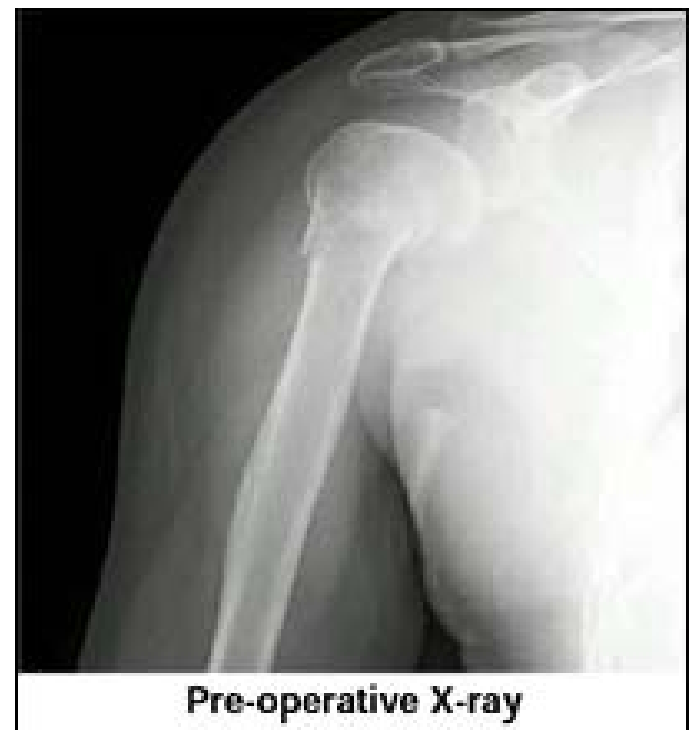

Fig 3: Two Part Frcture

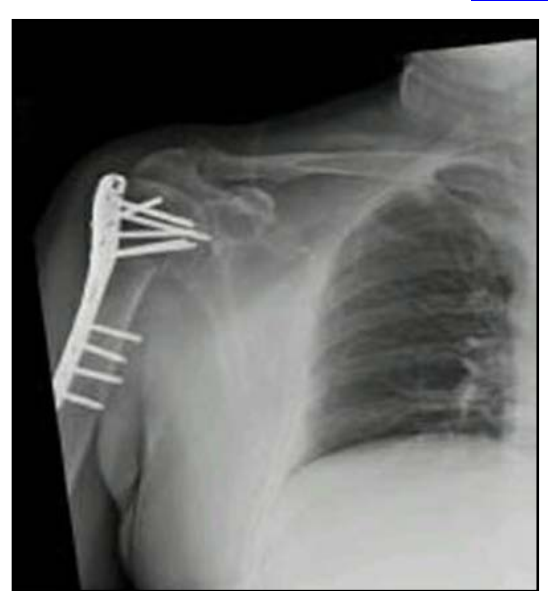

Fig 4: Post-Operative

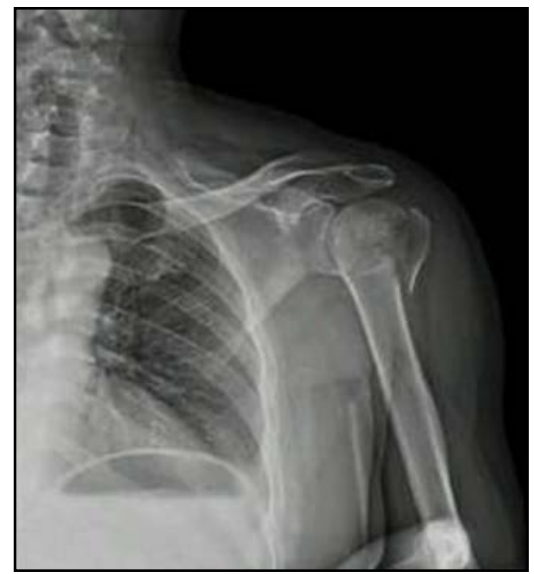

Fig 5: Pre-Operative 3 Part \#

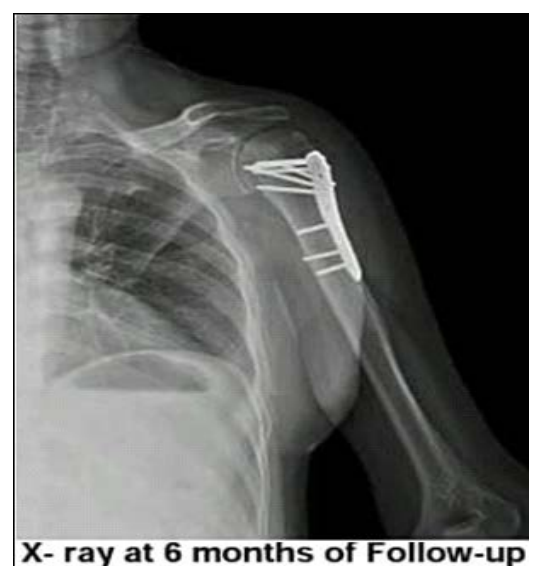

Fig 6: Post-Operative

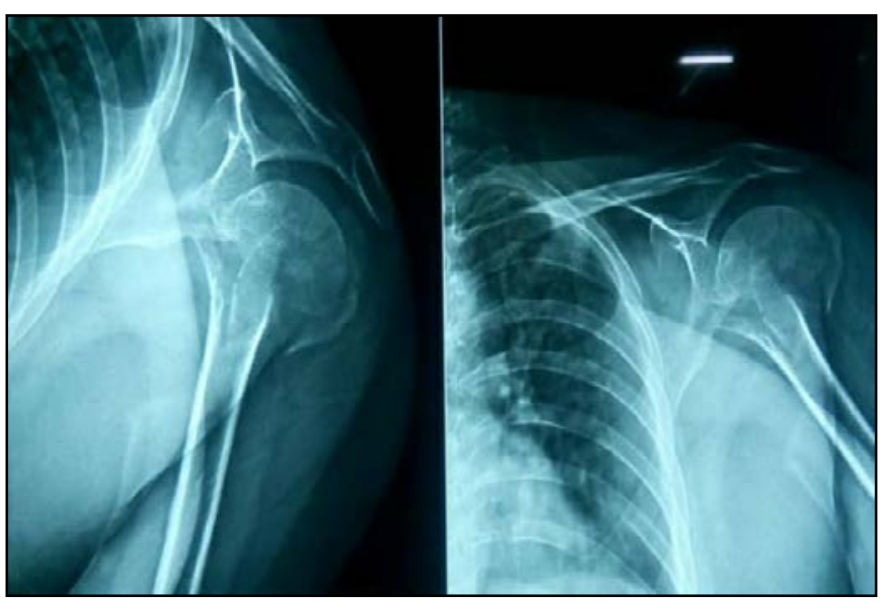

Fig 7: Post-Operative X-ray 


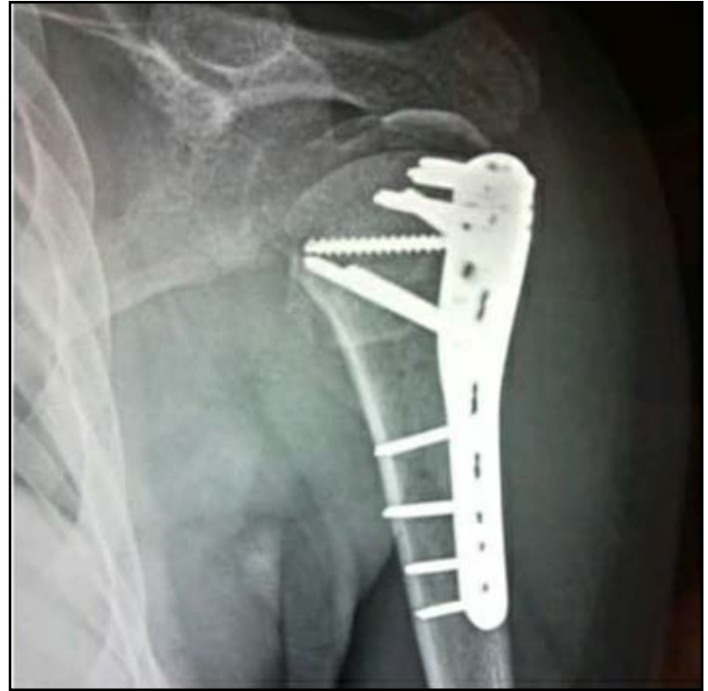

Fig 8: X- ray at 3 months of follow-up

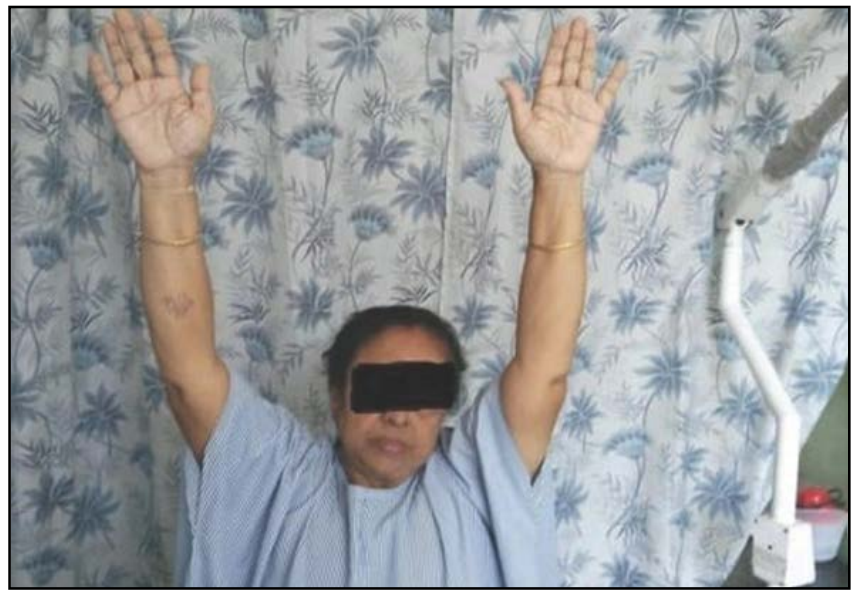

Fig 9: Post-operative follow up showing patient with 3 part fracture having good ROM

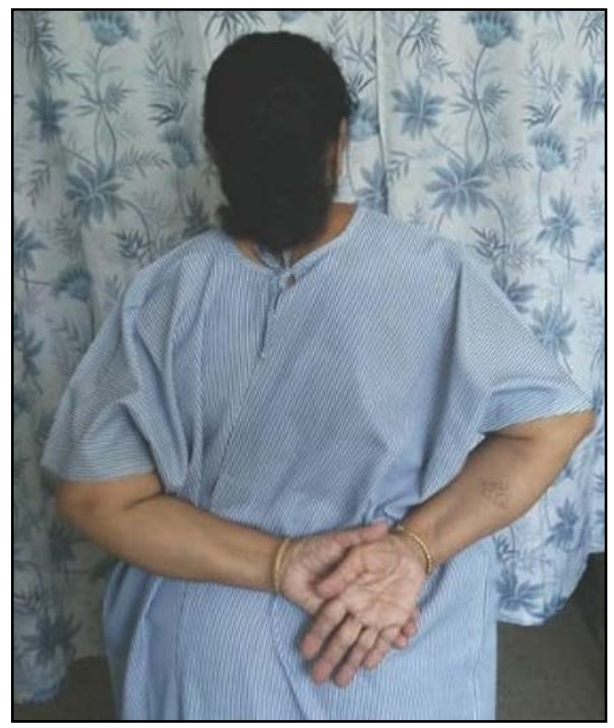

Fig 10: Post Op Range of Movement

\section{Discussion}

Proximal humerus fractures are one of the commonest fractures occurring in the orthopedics. They comprises of approximately $4-5 \%$ of the fractures at the hospital and are secondary only to hip fractures and distal end radius fractures in the elderly group. The incidence is approximately 3 per 1000 persons in a year and is rapidly increasing with age ${ }^{[1,2}$,

${ }^{3]}$ Proximal humerus fractures comprises of 2 to $3 \%$ of upper limb fractures. 75 percent of these fractures are seen in elderly group. 80 to $85 \%$ of these fractures can be managed by conservative treatment and the remaining 15 to $20 \%$ are displaced significantly and require some kind of internal fixation. 69, 70, 71.

The Neer 33, 40 classification system, published in 1970, is based on displacement of the parts and prognosis determined by head viability. He published results from the observation of 300 randomly selected proximal humerus fractures, focusing on the pattern of displacement rather than the location of the fracture lines. In outcome analysis, he focused on humeral head viability and the glenohumeral relationship. Fractures are classified by evaluating the displacement of the parts (head, shaft, greater tuberosity and lesser tuberosity) from each other.

\section{To meet the criteria of a part displacement}

- The fracture must be rotated more than 45 degrees or

- $\quad$ Displaced more than $1 \mathrm{~cm}$ from another fragment.

A proximal humerus with multiple fracture lines may be considered as one part fracture if there is no significant displacement

Two-part fracture is typically a surgical neck fracture in which the head with attached tuberosities is displaced from the shaft, a displaced greater tuberosity fracture, lesser tuberosity fracture or anatomic neck fracture is less common. Three part fracture which may include head include head dislocation, involve the surgical neck and one of the tuberosities, the greater tuberosity displaces more commonly than the lesser tuberosity. 88 In four part fracture all the parts are displaced and the articular head fragment is devoid of soft tissue attachments. The exception to this is the valgusimpacted proximal humerus fracture in which the head is displaced from the glenoid and rotated upward. The head may retain capsular and periosteal attachments along the medial calcar, which might account for the decreased rate of osteonecrosis in this fracture pattern.

Neer s criteria is based on

\section{Neer`s criteria}

1. Pain

2. Functional ability

3. Range of motion

4. Degree of deformity total score is 100

\section{Neer's Score: $>89$ units}

Excellent

Satisfactory $\quad 80-89$ units

Unsatisfactory $\quad 70-79$ units

Failure $<70$ units

\section{Conclusion}

Locking Compression plate fixation for proximal humeral fracture of all types without dislocation is a very good alternative to conservative management which provides good result with careful planning and execution

\section{References}

1. Anthony F, Palma De, Richards Cautilli. Fractures of the upper end of the humerus. Clin. Ortho. 1971; 20:73-93.

2. Neer CS II, Rockwood CA. Fractures and dislocations of the shoulder. In: Rockwood CA, Green DP (Eds): Fracture in adults, Philadelphia, PA, Lippincott, 1984, 675-721. 
3. Wijgman Rooler Patt, Raaymakers Marti. Open reduction and internal fixation of three- and four-part fractures of the proximal part of the humerus. JBJS (Am). 2001; 84:1919-1920.

4. Campbell`s Operative orthopaedics. Fracture about proximal humerus in adults. 10th Ed, 3:2990-2994.

5. Voigt C, Lill H. Fixed-angle plate fixation of proximal humeral fractures. Trauma Berufskrankh. 2005; 7(1):1014.

6. Mittlmeier TW, Stedtfeld HW, Ewert A, Beck M, Frosch B, Gradl G et al. Stabilization of proximal humeral fractures with an angular and sliding stable antegrade locking nail (Tragon P H). J Bone Joint Surg Am. 2003; 85(4):136-146.

7. Stedtfeld HW, Attmanspacher W, Thaler K, Frosch B. Fixation of humeral head fractures with antegrade intramedullary nailing [in German]. Zentralbl Chir. 2003; 128(1):6-11.

8. Mathews J, Lobenhoffer P. Results of the provision of unstable proximal humeral fractures in geriatric patients with a new angle stabilizing antegrade nail system. Unfallchirurg. 2004; 107(5):372-380.

9. Björkenheim JM, Pajarinen J, Savolainen V. Internal fixation of proximal humeral fractures with a locking compression plate: A retrospective evaluation of 72 patients followed for a minimum of 1 year. Acta Orthop Scand. 2004; 75(6):741-745.

10. Gardner MJ, Weil Y, Barker JU, Kelly BT, Helfet DL, Lorich DJ et al. The Importance of medial support in locked plating of proximal humerus fractures. J Orthop Trauma. 2007; 21(3):185-191.

11. Lill H, Hepp P, Rose T, König K, Josten C. The angle stable locking-proximal- humerusplate (LPHP) for proximal humeral fractures using a small anteriorlateral-deltoid- splitting-approach - technique and first results [in German]. Zentralbl Chir. 2004; 129(1):43-48.

12. Roderer G, Gebhard Erhardt J, Abouelsoud M, Kinzl L. The Non-Contact Bridging Plate: a new fixed-angle device for the minimally-invasive treatment of fractures of the proximal humerus-techniques and preliminary results. Unfallchirurg. [Epub ahead of print], 2007, 8.

13. Rose PS, Adams CR, Torchia ME, Jacofsky DJ, Haidukewych GG, Steinmann SP. Locking plate fixation for proximal humeral fractures: Initial results with a new implant. J Shoulder Elbow Surg. 2007; 16(2):202-207.

14. Andrew Crenshaw H, Edward Perez A. Fractures of the shoulder, arm and forearm in chapter 54; Campbell`s Operative Orthopaedics by Terry S. Canale, James H. Beaty 11th edition, 2008, 3384.

15. Thyagarajan DS, Haridas SJ, Jones D, Dent C, Evans R, Williams R et al. Functional outcome following proximal humeral interlocking system plating for displaced proximal humeral fractures. Int J Shoulder Surg. 2009; 3:57-62.

16. Zyto K. Non-operative treatment of comminuted fractures of the proximal humerus in elderly patients. Injury 1998; 29:349-52.

17. Michael A. Wirth. Proximal humerus fractures. Am Acad orthop Surg, 2002, 1-55.

18. Boileau P, Walch $\mathrm{G}$. the three-dimensional geometry of the proximal humerus: implications for surgical technique and prosthetic design. JBJS (Br). 1997; 79:859865.

19. Debevoise NT, Hyatt GW, Townsend GB. Humeral torsion in recurrent shoulder dislocations: A technique of determination by x-ray. Clin Orthop. 1971; 76:87-93.

20. Hill JA, Tkach L, Hendrix RW. A study of glenohumeral orientation in patients with anterior recurrent shoulder dislocations using computerized axial tomography. Orthop Rev, 1989, 84-91. 